Improving accountability for farm animal welfare: the performative role of a benchmark device

\author{
Josie McLaren and Tony Appleyard
}

Newcastle University Business School, Newcastle upon Tyne, UK

Corresponding author: Dr Josie McLaren, Newcastle University Business School, Newcastle upon Tyne, NE1 4SE, UK. Tel: +44 1912081549

Email: Josie.mclaren@ncl.ac.uk 


\title{
Improving accountability for farm animal welfare: the performative role of a benchmark device
}

\begin{abstract}
Purpose - The purpose of this paper is to investigate accountability for farm animal welfare (FAW) in food companies. FAW is an important social issue, yet it is difficult to define and measure, meaning that it is difficult for companies to demonstrate accountability. We investigate a proposed solution, the Business Benchmark on Farm Animal Welfare (BBFAW), and how it has disrupted the informal rules or culture of the market. Our research questions centre on the process of response to BBFAW and the necessary characteristics for BBFAW to play a performative role in the market.

Design/methodology/approach - This paper employs an analysis of published BBFAW reports (2012-2017) and case study interviews in five BBFAW firms, in order to address the research questions.

Findings - We present evidence of a dynamic, repetitive process, starting with recognition of the importance of FAW and BBFAW, followed by internal discussions and the commitment of resources, and changes in communication to external stakeholders. Three necessary characteristics for performativity are proposed: common language, building networks and expanding markets.
\end{abstract}

Originality/value - This paper reflects a socially important issue that is underrepresented in the accounting literature. The results provide an insight into the use of external accounts to drive collaboratively the social change agenda. The performativity process and identified characteristics contribute to expanding this literature in the accounting domain.

Keywords Business Benchmark on Farm Animal Welfare, benchmarks, farm animal welfare, performativity, ranking, disclosures

Paper type Case study 


\section{Introduction}

Farm animal welfare (FAW) is an important social issue, yet it is complicated by the fact that it is difficult to define and measure. Furthermore, there are no formal regulations surrounding its reporting in the public domain, so there is no standardised way for companies to communicate and for stakeholders to receive and interpret this information. This means that it is difficult to demonstrate accountability and for comparisons to be made across firms and over time. The purpose of this paper is to investigate a solution to this problem in the form of an annual ranking based on firms' narrative disclosures, the Business Benchmark on Farm Animal Welfare (BBFAW). Created with support from two founding NGO partners, Compassion in World Farming (CWF) and World Animal Protection (WAP), the aim of BBFAW is to raise standards of FAW, both in terms of underlying welfare practices and the reporting of those practices. Our overarching objective is to examine the process of response by firms.

The significance of FAW as a socially relevant issue continues to grow due to the scale of livestock production and changing societal views towards animal welfare. The global number of farm animals reared for food increased from 60 billion a year to just over 70 billion over a five-year period, with livestock comprising the largest use of agricultural land (CWF, 2013). Further increases in demand are forecast, driven by both population growth, projected to rise to 9.8 billion by 2050 (United Nations, 2017) and increases in GDP. Greater requirements for feed, forage, water and land lead to pressures to intensify farming methods (Tilman et al., 2001), posing moral and ethical questions surrounding FAW[1]. These issues raise strong feelings. For example, media exposure in Australia of live sheep being transported to the Middle East has led to calls for the reform of welfare standards (Animals Australia, 2018) and the export of live cattle to Sri Lanka as part of a government-backed scheme has raised questions of welfare through the supply chain (Knowles and Heanue, 2019). In the EU, a major study found that $94 \%$ of citizens believe that protecting the welfare of farm animals is important, with $82 \%$ of respondents saying that farm animals should be better protected than they are now (Animal Welfare Intergroup, 2016).

The BBFAW solution represents an attempt to effect large-scale change in the market. In this context, we define the market as an institution that exists to reduce the costs of exchange (Yarrow, 2015). Institutions are the 'rules of the game' governing the behaviour and decision-making of society in specific situations where these rules may be formal, such as laws and regulations, or informal, such as conventions or codes (North, 1990; Fligstein, 2001). This definition can be extended to include the activities that are governed by the rules (Yarrow, 2015). Our particular context is the disruption to the informal rules or culture (shared values) as a result of the introduction of BBFAW and the resulting impact on activities relating to FAW. Various actors are present, including managers, investors, customers, suppliers, NGOs and scientific researchers. For listed companies, investors play a key role as social norms may flow through the channel of portfolio investment into firms that support strong environmental and social performance (Dyck et al., 2018). Institutional investor activism is becoming the norm as 
a way to force changes in companies (Edelman Trust, 2018). Customers may demand welfare information, stating willingness to pay or revealing preferences for higher welfare (for example Chilton et al., 2006; Lagerkvist and Hess, 2011; Clark et al., 2017). NGOs may play a role in improving information and communication (Harvey and Hubbard, 2013), through lobbying to change rules and regulations or through direct contact with firms to instigate change in corporate behaviour (Adams and Whelan, 2009). Direct contact includes activist practice and media exposure (Vinnari and Laine, 2017), conflict arenas (Thomson et al., 2015), exercising power (Brennan and MerklDavies, 2014) or by interacting collaboratively (Deegan and Blomquist, 2006; Islam and van Staden, 2018). Managers within firms may be intrinsically interested in FAW and they may also view it as a potential source of business opportunity, both financial and reputational (Dawkins, 2017). Value may be created through 'good' welfare practices or be destroyed through adverse publicity surrounding 'bad' welfare. Because of this, firms may create a supply side or 'push' to increase welfare and welfare reporting, despite there being no legal requirement to do so (Bebbington et al., 2008).

In this paper, we propose that BBFAW has the potential to reduce the costs of transactions in the market through its provision of a solution to the problem of the definition and measurement of FAW. As information costs fall, it may modify actors' behaviour, including changes within firms to underlying animal welfare practices, internal accounting systems, resource allocation and external reporting. In the market it has the potential to reduce search costs relating to FAW information. If BBFAW becomes established and prevalent it will become the measure of FAW in the market i.e. it is performative. Performativity is a form of action that can effect change, described in the context of markets by Callon (for example, 1998). We use the performativity lens to investigate BBFAW, beginning our study at the time of the introduction of BBFAW and following it through the rankings published from 2012-2017 (BBFAW, 2018). We focus on BBFAW as a market device that calculates and articulates actions (Callon and Muniesa, 2005; Muniesa et al., 2007). We conduct a two-phase investigation where first we review published benchmark reports and website disclosures in order to establish a performative response by firms. Second, we explore managerial (and stakeholder) perspectives in greater depth through case study interviews. In particular, our research questions are as follows:

1. What is the process of response for performativity to occur?

2. What characteristics of the device are required for performativity?

Our findings suggest a dynamic repetitive process, with the potential for performativity increased if the benchmark has three key characteristics: it forms the common language (for internal and external communication), it assists with building networks (through linking actors in the market), and with expanding the market (for example to new companies, jurisdictions and wider stakeholder groups). 
Overall, we make three main contributions that will be of interest to both academics and practitioners. First, the research is centred on the socially relevant topic of the nonhuman animal which is just emerging in the accounting literature (see Gallhofer et al., 2006; Laine and Vinnari, 2017; Vinnari and Laine, 2017). As accounting scholars we have an opportunity to assist wider communities by raising awareness and understanding of issues of social responsibility, accountability and sustainability (Gray, 2010; Guthrie and Parker, 2017) and social injustice (Dillard and Vinnari, 2017). Our case study evidence provides primary data, in contrast to much social and environmental accounting research, which tends to be desk-based, relying on secondary data (Owen, 2008; Deegan, 2017). The results will provide insights for companies and stakeholders with an interest in practices and policies surrounding FAW. Second, on a more general level, we demonstrate the power of an external account to intervene in and shape a market, not in a formal way through rules and regulation, but by disrupting the informal rules or culture. Behavioural changes are achieved in a collaborative way (rather than through conflict, for example as described by Thomson et al., 2015). Finally, evidence on the process of and characteristics for performativity reveals insights to participants considering ways of shaping informal rules.

The paper proceeds as follows. In the next section, and in order to inform our theoretical framework the literature on performativity and calculative devices is discussed. In the subsequent section we present the FAW market, setting BBFAW in its environmental context. Research methods and findings are presented in section 4, followed by a discussion in section 5 in which the characteristics of performativity are developed. Section 6 concludes.

\section{Literature Review}

Two interrelated spheres of the literature are relevant to this study. First, we discuss performativity as our overall guiding framework, in order to understand the shaping of the informal rules of the market. Next we consider benchmarks as calculative devices within the market, enabling the articulation of activities.

\section{Performativity and the shaping of markets}

The concept of performativity has its roots in a book by Austin (1962), although it has been noted that Austin never used the term performativity (Cabantous et al., 2016). A performative statement is one in which 'to say something is to do something, or in which by saying something we are doing something' (Austin, 1962, p12). The example often cited for this discourse and action is an authorised person saying 'I pronounce you husband and wife' (Gond et al., 2015). From this beginning, a key piece of research was conducted by Butler, 1993, who stated that performativity 'is not an act, nor a performance, but constantly repeated "acts" that reiterate norms' (Butler, 1993, p240). This repetition is fundamental to performativity. 
Performativity has been applied as a framework in many disciplines, including philosophy, gender studies, sociology and organization studies (Gond et al., 2015) and it has recently appeared in the accounting literature (for example, Vosselman, 2014; Revellino and Mouritsen, 2015; Vesty et al., 2015). In relation to the functioning of markets, Callon (1998) developed the 'performativity of economics thesis' which states that 'economics, broadly defined, performs, shapes and formats the economy, rather than observing how it functions' (Callon, 1998, p2). In the context of options markets, the Black-Scholes model has been described as performative due to its impact on trading strategies, which ensured that the model shaped the markets that it was designed to describe (Mackenzie, 2003; Mackenzie and Millo, 2003; Mackenzie, 2006a). Within the firm, Vesty et al. (2015) illustrated how a carbon number was elevated to become a pivotal actor in organisational practice.

A key feature of performativity is that it is not an instant phenomenon, rather it is realised after the 'long and collective effort' by market participants (Callon, 2007, 313), suggesting a dynamic, processual process. These actors are part of a network and they participate collectively in the 'development and diffusion of innovations and which via numerous interactions organise the relationships between scientifico-technical research and the marketplace' (Callon et al., 1992, 220). The networks, which evolve over time, are arranged around three main poles, 'distinguished both by the actors constituting them and by the types of intermediaries that these actors put into circulation' (Callon et al., 1992, 220-221). A scientific pole that produces certified knowledge; a technical pole that develops and transforms artefacts; and a market pole that refers to 'practitioners' (Miller and O'Leary, 2007, p709). This framing will be used as a basis for our consideration of the network surrounding BBFAW.

\section{Benchmarks and rankings as calculative devices to achieve performativity}

Devices have agency - they act or they make others act (Muniesa et al., 2007). Calculative devices articulate actions and are viewed as a necessary component in the construction of markets (Callon, 1998; Callon and Muniesa, 2005; Giamporcaro and Gond, 2016). A calculative device may ensure that values can be assigned (Callon, 1998) and comparisons drawn (Rooney and Dumay, 2016), thus facilitating encounters between agents with unequal calculating ability (Callon and Muniesa, 2005). These devices may be employed to influence the informal rules or culture, in contrast to a change in the formal rules relating to that market. Thus, calculative devices facilitate performativity through their role as mediating instruments, helping to shape the world they describe (Mackenzie, 2006b; Callon, 2007; Miller and O'Leary, 2007; Cochoy et al., 2010; Roscoe and Chillas, 2014).

Benchmarks and ranking schemes are examples of calculative devices that enable calculation through the assignment of numbers to influence perceptions and create or shape markets (Schultz et al., 2001; Espeland and Sauder, 2007; Sauder and Espeland, 2009; Kornberger and Carter, 2010; Jeacle and Carter, 2011; Pollock and D'Adderio, 2012). They may 'translate the invisible and qualitative into the visible and quantitative' 
(Kornberger and Carter, 2010, 330), creating order amongst entities in a process described as 'qualculation', where qualities are turned into quantities (Miller, 2001; Callon and Law, 2005; Cochoy et al., 2010) and calculation and judgment are intertwined. This calculative practice may represent an interface between a 'purely objective' calculability and a 'purely subjective' judgment that enables organizational actors to make decisions (Cabantous et al., 2010). In this way rankings can offer new interpretations of a situation (Espeland and Sauder, 2007), with the power to organise social action (Vesty et al., 2015), providing structure and 'dissipating the opacity of the market' (Karpik, 2010, 44), creating hierarchical relationships and competition between entities who may not otherwise be in competition with each other (Kornberger and Carter, 2010). This competition may then trigger behavioural responses as the constituent entities in the ranking adapt in order to improve their position, for example in the form of a change in strategy (Kornberger and Carter, 2010; Skærbæk and Tryggestad, 2010; Revellino and Mouritsen, 2015) or structure and practice within the firm (Shore and Wright, 2015; Slager, 2015). Therefore, rankings cannot be separated from a study of organisational response (Pollock et al., 2018).

Accounting is implicated in the calculation of benchmarks and rankings because these devices are an account of the underlying accounting information from which they are constructed. This information may be drawn from a variety of sources and types (for example external narratives and unpublished data which may be qualitative or quantitative). Accounting has the potential to not only reflect, store and transport, but also to perform (Vosselman, 2014). However, the extant accounting system may limit the scope of accountability (Dillard and Vinnari, 2018) so that new forms of accounting are required in order to achieve performativity. However, there may be limits to performativity. First, related to construction of benchmarks and rankings, qualculability is not a trivial matter as it takes effort to create calculation and judgment, and to consider nonqualculability (Callon and Law, 2005). Other issues relate to organisational response. New calculable visibilities could be contested instead of being a conduit for greater comparability, consensus and conservation (Sullivan and Hannis, 2017). Benchmarks may create adverse incentives, with unintended consequences (see for example Willmott (2011); Tourish and Willmott (2015) on university ranking schemes). Alternatives may exist that substitute for, or conflict with a benchmark, meaning that trade-offs must be made. Finally, benchmarks may be ignored if there is no perceived relevance to the firm.

The first phase of our empirical analysis, a detailed review of published BBFAW reports and constituent firm websites, will enable us to assess the performative response in respect of the external narratives (external accounting) released by the constituent firms. The second phase, case study interviews, facilitates further evaluation of the potential for and possible limits to performativity. In this phase, the two research questions were used to guide the analysis. 
In section 4, we explore in more detail our research setting and data collection methods that will enable an empirical assessment of these research questions. First we discuss in more detail the FAW market, setting BBFAW its environmental context.

\section{The FAW Market}

In our conception of the market, we include the rules and activities surrounding FAW. However, there are fundamental complexities as FAW is difficult to define in an objective way and it is difficult to measure. At a high level, welfare refers to physical and mental wellbeing of animals as sentient creatures (for example Boissy and Erhard, 2014; Dawkins, 2015), relating to needs and wants (Dawkins, 2012). However, it is a concept based on human expectations (Harvey and Hubbard, 2013; Webster, 2013). Measurement of wants is complex and contested - many animal welfare researchers study emotions and consciousness but this is subject to challenge in parts of the scientific literature (Dawkins, 2012). Measurement of needs relates to animal health and management and is less controversial but there are still a number of choices to be made over how to measure, for example input-based measures (such as housing systems and practices) and outcomes-based measures (such as species-specific welfare indicators).

\section{Shaping the market: formal and informal rules}

Formal rules may define a legal base, enabling or preventing trade. In the UK (the context for our case studies), formal rules provide some assistance with the basic definition of FAW. Farmers are legally responsible for their animals' welfare, with a duty to provide for their needs under the Animal Welfare Acts, where the minimum standard of welfare is based on the provision of needs and the avoidance of suffering. Current legislation includes the UK Government's 2006 Farm Animal Welfare Act and the Welfare of Farmed Animals (England) Regulations 2007, underpinned by the Farm Animal Welfare Council's (FAWC) 'Five Freedoms'[2] and the 1997 EU Treaty of Amsterdam, which contains a protocol on the protection and welfare of animals, recognising their sentience (UK Government, 2017)[3].

Existing legislation is not without controversy. For example, a 2009 FAWC report claimed that the Five Freedoms reinforce the negative image of farming and food production and that the minimum FAW should be defined in terms of an animal's quality of life over its lifetime on the farm, during transport, at gatherings and at the abattoir, including the manner of its death. Scientific studies have been conducted to assess the suitability of the Five Freedoms as a definition of welfare (for example, McCulloch, 2013). A more general difficulty with the formal rules of legislation (and regulation) is that any change would require a long timescale for implementation, with an uncertain probability of success. Furthermore, legislation only applies to defined jurisdictions (for example an individual country or the member states), it does not apply globally. Threats to this legislation exist as a result of political instability, for example surrounding Brexit and the potential impact of trade issues (such as Transatlantic Trade Partnerships). Overall, 
formal rules may be seen as providing a minimum standard but they don't enable a comparison between firms, they don't promote competition and it is difficult to compare FAW performance across different firms and legal jurisdictions.

Informal rules add to the baseline established from the formal rules. Relating to conventions and codes (North, 1990; Fligstein, 2001), informal rules have no legal or regulatory status at a point in time, rather they describe the culture or shared values in the market (although it is conceivable that informal rules could be formalised). In the context of FAW, informal rules include for example farm assurance schemes. These schemes are voluntary and they are used to encourage and monitor compliance with baseline formal rules and specified additional requirements (for example, Red Tractor, RSPCA Freedom Foods and Soil Association schemes). They can provide a role in driving higher standards, in providing robust auditing and assurance processes and providing information (BBFAW 2017 report, p40). However, these schemes have been criticised as offering little assurance to consumers beyond simple compliance with minimum requirements. Furthermore, they focus primarily on inputs to animal management rather than welfare, they may encompass other aspects such as food safety, they have limited geographic scope, they may be industry-driven and they tend to be speciesspecific (Martin and Blache, 2014). If a great majority of producers sign up to a particular scheme, differentiation is difficult as schemes are effectively an informal licence to operate (Martin and Blache, 2014). In order to differentiate, firms may need to sign up to a variety of schemes which may have conflicting specifications, creating problems over external communication and internal actions (see Pollock et al., 2018, for the issues created with dealing with multiple ranking schemes). These factors increase the attractiveness of a single scheme that encompasses a variety of species and jurisdictions, and which enables differentiation.

\section{BBFAW and performativity}

For the functioning of markets, stability in the rules is generally required but this does not preclude changes to those rules. A change is predicted if that change reduces the cost of transacting (Yarrow, 2015). BBFAW is an example of such a change, introduced to reduce information costs of transacting around FAW. These costs include search costs for firms and their stakeholders. BBFAW is an attempt to shape the informal rules, in the form of an external account, 'produced by, or on behalf of, individuals who are beyond, or outside, the control of the entity that is the subject of the account' (Thomson et al., $2015,810)[4]$. However, cost reduction is not sufficient to promote a change in the informal rules. Other qualities are required. In particular, the BBFAW needs to facilitate the creation of the network (see Figure 1), defining the relationship between the poles. In our context we define the scientific pole to comprise actors who produce knowledge through scientific trials, reports and articles, for example research institutes, NGOs and universities. Conceptualisation based on science lends credence and authority (Brennan and Merkl-Davies, 2014). This pole helps the creators to determine how best to define and measure FAW. The technical pole represents BBFAW creators - members of the founding NGOs and their independent Technical Working Group (created in order to 
develop and transform the metric)[5]. The benchmark companies are also part of this pole as FAW is managed within the firms and they produce and publish the narrative disclosures on which BBFAW is based[6]. Finally, because of the way we have defined the market as the rules and activities, in our context we characterise the market (practitioner) pole as the stakeholder pole representing stakeholders such as investors, customers, and suppliers. Taken together, the three poles constitute the network of activity within the market.

Figure 1 about here

Performativity may arise in three key areas: external narratives, narratives within the firm and decisions over FAW practices. First, in terms of external narratives, BBFAW may disrupt extant reporting if constituent firms choose to align their disclosures with the framework provided by the BBFAW questions. This external narrative could be within the annual report and accounts or as part of a wider set of the information released by firms, for which company websites are a useful means of enabling connectivity in corporate communications (Brennan and Merkl-Davies, 2018). However, such disclosures involve subjectivity as they are not covered by accounting standards. Companies face decisions over what to disclose (as well as how to define and measure FAW). BBFAW may provide a solution through its definition and measurement of FAW, thereby acting as a coordination mechanism between and within poles, providing a means of drawing comparisons between companies and over time. However, such a change may provide only partial performativity, as there may be no real effects on underlying welfare practices - firms may be simply 'doing the document not doing the doing' (Ahmed, 2007). Full performativity would come into play if internal accounting systems were changed so that BBFAW becomes part of the information set used for decision-making (including for resource allocation) and/or if it changes behaviour and practices surrounding FAW for the firms and their suppliers. In this situation, BBFAW would be acting as an intermediary to define and complete the network, changing the culture or informal rules of the market institution.

In the case of BBFAW, failure to achieve a change in the informal rules may indicate that actors do not value FAW, or that the process for achieving improvements was flawed. Resistance to improvements in FAW is possible if the demands are too great when evaluated against other strategic priorities (Dawkins, 2017) so that economic factors mean that disclosure is weak (Milne et al., 2009) and engagement with BBFAW does not happen. There is scope for challenge to the construction of the metric (Sullivan and Hannis, 2017) including the qualculation process (Callon and Law, 2005) and the means of information collection. Construction based on narrative disclosures means that constituent firms are subject to the cycle of accountability, even if they choose to ignore it (Messner, 2009). The ranking may create adverse incentives (Willmott, 2011; Tourish and Willmott, 2015). Other ranking schemes that substitute for, or conflict with, BBFAW may exist and serve to reduce performativity, depending on their relative importance. These areas are developed further in the following sections. 


\section{Research Methods and Findings}

Our empirical evidence is established through an analysis of the 2012-2017 BBFAW reports, together with a review of the websites of Benchmark firms (phase 1) and case study interviews (phase 2). An interpretive approach, using qualitative data, is the appropriate methodology in an exploratory study such as this (Crane, 1999), with case studies well established as a means of gathering in-depth information on factors relating to 'how' and 'why' research questions (Scapens, 1990; Otley, 1999; Yin, 2018), including the reaction of managers to particular lobby group concerns (Deegan and Blomquist, 2006). The case study method provides the opportunity to study a phenomenon in its own context, and it can also permit an understanding of the process of change over time (McLaren et al., 2016). The analysis of more than one case reduces the prospect of failing to uncover rival explanations (Brownell, 1995). Case study analysis is preferable to a review of disclosures on their own, since such narratives may reflect the creation of a preferred reality that does not reflect underlying practices. This has been described in various ways in the literature, including 'greenwashing', an insincere display of concern for the environment shown by an organisation (Guidry and Paten, 2010; Lyon and Maxwell, 2011; Mahoney et al., 2013; Testa et al., 2018); 'gaming strategies', managing appearances without improving the characteristics the factors are designed to measure (Espeland and Sauder, 2007); 'organised hypocrisy' adopted as a means of meeting conflicting stakeholder demands (Cho et al., 2015); and 'institutional appropriation' where organizations are unlikely to change in substantive ways, appropriating the environmental agenda so that issues remain unaddressed (Larrinaga-Gonzalez and Bebbington, 2001). All of these practices can serve to undermine confidence and credibility. They may reveal performativity in terms of external narratives but not in terms of narratives within the firm or changes to underlying welfare practices.

A number of UK-based Benchmark firms were contacted in 2014 and an interview request made. Five companies agreed to take part. These firms, which are the main players in their field with a reach extending to a major proportion of the UK population, provided a spread of BBFAW tier rankings and industries. Respondents' roles varied, although they all held responsibility for some or all aspects of FAW within their firms. Only one firm had a dedicated FAW manager but within each firm, agricultural specialists worked alongside other managers (for example sustainability managers) to ensure the delivery of the objectives in respect of animal welfare.

Semi-structured interviews were conducted with the appropriate respondent/s identified by the firms, with interviewees agreeing to participate on the understanding that they and their firms would remain anonymous. Both researchers attended all five interviews, three of which were recorded and transcribed and two relied on extensive notes taken by both interviewers (as requested by respondents)[7]. Following the interviews, the researchers read independently the transcribed recordings and notes, highlighting quotes of interest and areas for discussion. They then met to agree on the 
presentation of the evidence. If necessary, points of clarification were pursued with the respondents. Summary information on participant firms and the interview process is provided in Table 1 below.

Table 1 about here

\section{Phase 1: Review of BBBFAW reports and websites of constituent firms Construction of BBFAW}

Our review covers the first six Benchmark reports (covering the period 2012-2017). Firms are included in BBFAW based on their animal 'footprint' and they are public, private, joint ventures or cooperatives, with the set largely dominated by US and European firms (for example Aldi Nord and Sud, Costco, Marks and Spencer, McDonalds, Tesco, Tyson Foods, Walmart). In 2016 the reach extended to Australasia (Fonterra, Wesfarmers and Woolworths), (BBFAW (2012-2017), full details available on the website). The firms are divided into three groups according to Industry Classification Benchmarks (ICB): Food Retailers and Wholesalers, Restaurants and Bars, and Food Producers. There is no payment required by constituent firms, or voluntary opt-in, and internal information and audits are not necessary to construct the rankings. A problem with the use of private (undisclosed to the market) information concerns the storing of that information which can create data confidentiality issues (Martin and Blache, 2014). This does not arise with the use of public information.

FAW is defined and measured in BBFAW through a series of questions which encompass input and output measures, reflecting expectations of welfare that exceed the legal baseline. Questions cover the entities' own businesses, as well as operations in global supply chains (which suggests that a company cannot side-step a welfare issue by ringfencing its business so that potentially detrimental aspects of welfare further up the supply chain are excluded). Questions in the 2017 report reflect management commitment and policy, governance and management, leadership and innovation and performance impact (BBFAW, 2017). Performance impact questions (scored for the first time in 2017) represent an attempt to capture specific welfare measures (needs and wants), rather than policies and management surrounding welfare, thus connecting the scientific pole to the technology pole. Of the 15 questions, 14 are input-based and only one question is outcomes-based. All of the questions relate to the prevention of negative welfare, rather than the provision of positive welfare. Each question is marked according to a scale, with a range of marks available, from 0 (no reported information) through to maximum marks (for full reporting of the specific information). The range of available marks varies across questions (BBFAW, 2012-2017).

The final stage of the ranking construction is the assignment of each firm into one of six tiers based on their overall scores, from Tier 1 (indicating companies that have taken a leadership position), down to Tier 6 (where animal welfare does not appear to be on the business agenda) (BBFAW Reports, 2012-2017). See Table 2 for a time-series of the number of firms in each tier. Such a ranking system enables a comparison across entities 
and across time, making different things visible, offering a new social construct (Gray, 2013).

The trend in BBFAW results

A summary of the published BBFAW results is presented Table 2, which provides information by year on the number of companies in each tier, average tier value, average score and the percentage of firms publishing their farm animal welfare policy. There has been a steady increase in the number of constituent companies over time, demonstrating an extended reach for BBFAW. The overall average score and the percentage of firms publishing FAW policies or equivalent documents have increased while the average of the tier value for all companies each year has decreased over time (indicating an improvement in scores). These results suggest that, since the first publication of BBFAW, firms have responded by changing their external narrative in line with BBFAW questions.

Table 2 about here

From the reports it is apparent that a number of high profile firms have risen steadily through the rankings, including for example Marks and Spencer, Waitrose, Greggs, Tesco and Premier Foods. New firms and firms outside of the US and Europe tend to locate in the lower tiers but many demonstrate upward movement over time. In order to improve their score, companies are aligning their disclosures with BBFAW criteria, demonstrating an element of performativity. Fluctuating scores are apparent for some firms (for example Whitbread, Marfrig), indicating that there could be a change in priorities, a failure to keep up with the changing requirements of BBFAW, and/or a failure to publish relevant information by the census date. A group of firms, largely from outside the UK and US, continues to locate in the bottom tier, suggesting no disclosure or that disclosures do not align with the Benchmark.

\section{Reflecting on the scope for performativity}

Performativity may be enhanced through actions taken by the creators and through the firms' responses to BBFAW rankings. There is evidence that the creators are working to make BBFAW performative in terms of establishing, strengthening and expanding the links forged by the benchmark. Sponsorship by CWF and WAP and their representation on the TWG foster links between the scientific and technical poles, with this link strengthened further by including veterinarians on the TWG. However, given the scientific evidence suggesting that positive welfare is not simply the absence or reduction of negative experiences but also the expression of positive ones (for example (Greiveldinger et al., 2011; Dawkins, 2012, 2015; Boissy and Erhard, 2014) and the fact that there is an emerging field in animal welfare surrounding positive emotions relating to environmental enrichment and the improvement of human-animal relationships, future iterations of BBFAW could usefully look towards this emerging area to strengthen the link from the scientific pole. Connections within the technical pole are forged through engagement with companies and connections are made to the stakeholder pole 
through direct involvement with investors (such as roundtable discussions between the NGOs, companies and investors). The latter connections are designed to ensure more investors signal the importance they assign to FAW (as a way to encourage firms to improve their scores). The BBFAW creators have launched the first Global Investor Statement on Farm Animal Welfare, which has been signed by 23 institutional investors representing almost $f 1.9$ trillion in assets under management (BBFAW 2017, p48). These investors are based across North America, Australia and Europe[8]. The Statement recognises (amongst other things) FAW as an important issue, with BBFAW a tool for food companies to manage their FAW issues and as a framework to guide their reporting on FAW (BBFAW 2017, p49). Signatories also commit to engage with companies and with evolution in the Benchmark. This is further evidence of BBFAW providing information to enable connectivity in the network, placing investors at the heart of the system.

The BBFAW creators employ direct actions (through increasing the number of companies and jurisdictions covered) and indirect actions (through engagement with international investors). This expansion could not be achieved via formal rules (legislation and regulation) without international cooperation. Engagement with firms, investors and other interested parties ensures that different parts of the network can contribute to the future direction of BBFAW in a timely manner. Such an agile response is not possible with legislation.

In terms of the firms' response, a further way that we may gauge performativity is by looking at whether they communicate their BBFAW results externally. Of the 99 companies included in the 2016 benchmark, 24 explicitly referenced BBFAW either in annual reports, sustainability reports, website or media releases (BBFAW 2017, p47). A website search by the authors in 2018 found that 21 out of 110 BBFAW 2017 firms mentioned BBFAW on their websites, as shown in Table 3. The majority (although not all) of the firms are UK-based, both public and private. They locate in the top three tiers of the ranking, suggesting closer engagement with BBFAW, and/or strategies that align with higher welfare. Company statements refer to BBFAW as a validation mechanism, and importantly, as an influencer of practice (Marks \& Spencer and Waitrose), suggesting performativity. There appears to be no mention of BBFAW on the websites of companies locating in the lower tiers. A lack of engagement could be due to a number of reasons, for example customers do not care about FAW, the firms do not understand the benefits, or FAW is not part of strategy (BBFAW 2017, p7). For the latter situation, firms may choose to compete along other dimensions (for example price) or they may have other more pressing sustainability issues to contend with (for example human rights issues). However, this does not rule out performativity. Through BBFAW a change in the informal rules has been created but not all firms have to be fully engaged in this change. This point is discussed further in the following section.

Table 3 about here 
To summarise, through a review of BBFAW reports we have found evidence for performativity, demonstrated by an improvement in the average score over time (even when the number of firms is increasing), an increase in the number of firms publishing FAW policies, enhanced investor engagement and company statements suggesting that BBFAW influences practice. Performativity is enhanced by the creators through linking the poles of the network and reaching out to new areas (jurisdictions, companies and investors).

\section{Phase 2: Case Study Findings}

The notion of the FAW network formed the structure of the interviews, with questions divided into three key areas:

1. Scientific: Definition of and objectives surrounding FAW and the underpinning science

2. Technical: Systems and processes including auditing and assurance, internal systems and external reporting

3. Stakeholders: Engagement with groups including customers and investors

With the five case firms, all respondents recognised the difficulty of defining and measuring FAW. They emphasised that that legislative requirements must be met and even exceeded but there was evidence of variation in what constituted good FAW and therefore what they were trying to achieve. This reflects the subjective nature of FAW and suggests a place for a tool that provides some guidance in this area. All firms had objectives that concerned farm animals, ranging from general statements about 'doing the right thing' by selling 'food that you can trust', to objectives concerning general health, welfare, physical and mental well-being, to highly specific criteria for particular species. These objectives could extend beyond FAW with an awareness that actions elsewhere in the firm (i.e. non-food related) must not indirectly compromise the corporate image relating to animal welfare. Also, there was recognition that there are sustainability trade-offs to be made. For example, interviewees in two firms cited the desire for higher welfare versus with a desire to reduce the carbon footprint, thus acknowledging that higher FAW involves complex trade-offs that must be balanced. Case firms were either working directly with NGOs (such as RSPCA), conducting research on their own farms or with suppliers, and/or sponsoring independent research into improvements in their understanding of FAW. In this respect there was already a link in the network between the scientific pole and the companies (as part of the technical pole) but prior to BBFAW such a link was not necessarily obvious to other market participants.

Our case study interviews revealed a systematic chronological process or roadmap to performativity, as illustrated in Figure 2. This roadmap provides an answer to our first research question, concerning the process of response to the Benchmark. Respondents mentioned this process as a 'journey' rather that a set of actions that can be delivered in one go, thus reinforcing the dynamic repetitive nature. The first step is a recognition of the importance of FAW and BBFAW, internally and/or amongst stakeholders. Of 
course, recognition of FAW may well have occurred before the first BBFAW rankings were published but recognition of the benchmark is also required. Second, through the desire to engage in a more active way, internal discussions take place, resources are committed, and suppliers become involved. Third, reporting to external stakeholders can take place. The process is then repeated, with review and consultation prior to publication of the next iteration of BBFAW. The circular depiction of this process reflects the fact that repeated acts are necessary for performativity (Butler, 1993; Cabantous et al., 2016). This distinct process is employed to frame the evidence that is now presented. Illustrative quotes are provided to reinforce the points being made, with emphasis added by the authors in bold. Full discussion takes places in the following section.

Figure 2 about here

Process of Performativity

1. Recognition of the importance of FAW and BBFAW

Respondents in four of the firms stated that their businesses and their stakeholders recognised the importance of FAW and they had already had policies in place at the time of the publication of the first BBFAW report. This was apparent in a number of ways, including the existence of teams responsible for FAW and the gathering of formal and informal evidence from stakeholders, for example:

We get more queries on farm animal welfare than on anything else. Animal welfare is at the top of our agenda. (Company $C$ )

We obviously listen to our customers; we actually get feedback, I think it's quarterly, on a number of different social, ethical, welfare criteria and where they feature in the customer concerns, and animal welfare is in there... It's usually pitching in in the top five. So, you know, maybe 20 that we've tracked. So we know that our customers care; we know that they expect us to do the right thing, and we try our best to do that. (Company D)

It's written in our constitution, we have to demonstrate fairness and equality. We take that view on everything that we do. (Company E)

The above quotes provide examples of the clear potential for connections between the technical pole (the companies) and customers in the stakeholder pole. They also show that behaviours around FAW reflect the ethos of the firms. Companies B, C and D recognised the potential importance of BBFAW whereas the respondent in Company $E$ questioned what it added for them. At this initial stage (when BBFAW was first published), there was limited support for BBFAW adding anything new. This point will be discussed further below.

Company A was an exception to this pattern. FAW was not a key strategic priority so the initial reaction was that BBFAW was not significant - it was just another report. However, after a period of reflection, this view was revised: 
The Business Benchmark on Farm Animal Welfare has, I think, flagged up with us that other larger companies with greater resource have moved further on than (Company A), and that we are still at an early stage of being able to set policies on that level... Clearly now, the market has moved on and we haven't quite kept pace, so we now need to look at animal welfare as an issue that we need to start working on. (Company A)

Thus BBFAW provided the initial trigger for changes in priorities around FAW, as the ranking results suggested that the firm was lagging behind its competitors. The respondent implied that larger firms will have greater resources so will be further ahead in terms of welfare. However, the authors would contend that it is a matter of priorities, rather than size. A larger company doesn't necessarily have more resources to devote to FAW - but it is correct that resources are vital, and we discuss these in the subsequent stage in the process.

\section{Internal narratives and commitment of resources}

Following the recognition of the importance of BBFAW and FAW in the case firms, the second step concerns internal discussions and the decision to commit resources. Respondents in four firms cited examples of how BBFAW was influential in these discussions. Evidence from respondents in Companies $A, B, C$ and $D$ suggested that BBFAW is driving changes in behaviour, from highlighting new practices and strengthening existing practices, for example:

It's been influential in highlighting what we need to do. That has driven discussions about, "Right, this is where we are now, this is ideally where we would like to be to be comfortable. Here's a provisional plan about how we can potentially get there"... We need to debate internally what those standards should be and solicit external advice from external auditors on what standards are achievable. We need to talk to our suppliers. (Company A)

We are starting to see a change in our behaviour and that's where something like the Business Benchmark will probably be influential in trying to promote that and to drive benefit elsewhere and outside of the UK, in Western or Northern Europe... I think it will help make sure that welfare standards are always at the forefront of people's minds and it's across the entire business group. (Company $B$ )

I find it very useful to help me establish, am I where I should be? And also to help influence people internally as well. If you can say, "Well look, this is where we've pitched ourselves, this is where we want to be, the competitor set is moving." That's really good... So we're on a journey, absolutely on a journey, and in some areas, much further forward, than others. (Company $D$ )

Influence is a key word that was cited by these firms - for identifying gaps, promoting outside of the UK and for benchmarking. Improvements in FAW require a strategic commitment. BBFAW is available as a framework, forming a target when there may be multiple targets. From this recognition, resources can be committed to changing practice (for example improvements in welfare standards) and if necessary, decision 
made concerning how the firm should be organised and structured, with a review of the underlying accounting information that is required in order to move forward. Collectively this influence would not be possible with assurance schemes as an alternative means of changing the informal rules, for the reasons identified in the previous section.

\section{External narratives}

Narratives should reflect underlying practices surrounding FAW and firms must align their disclosures in order to improve their scores. However, BBFAW contains very detailed measures on highly specific aspects of FAW that the companies may not wish to place in the public domain. There is a balance and it is vital that there is agreement within the firm on this trade-off. Whilst it may be relatively easy to decide on disclosures surrounding policies, disclosure decisions concerning performance reporting are potentially more controversial. This will be explored more fully in the following section.

Disclosure changes can take a number of forms, from an absolute increase in disclosure (more information), to re-presentation of information, to explicit promotion of BBFAW results in stakeholder communications. This communication reinforces the connections between the technical and stakeholder poles. Respondents in companies B, C and D confirmed that they have modified their narrative disclosures to conform to the requirements of BBFAW, with the firms both increasing and re-presenting FAW information. For example:

The Benchmark is an exercise that's allowed us to see we've got a great story to tell but it was all hidden all over the place. So I think that it has been good and it will allow us to focus on how we need to be get more reporting about what we're doing on welfare, and it will allow us to change where all that information is on the website. (Company B)

It certainly will change how we communicate on some things. (Company D)

Within Company A, respondents acknowledged that they were not yet at this part of the process:

It will take time and we would want to be $100 \%$ secure that we felt we were in a good place and we had a good story to tell before we started to put messaging out to the customers... So we know this is a one, two, three-year programme that we're going to have to start entering into and slowly move ourselves up. (Company $A$ )

The above respondent emphasises the idea of the 'journey' around FAW which can take a number of years. This is not an excuse for taking time over improvements. It is not possible to jump immediately to a much higher position, as organisational culture needs to change before reporting to external stakeholders can take place, reinforcing the point that BBFAW can drive behavioural changes. Company $A$ is still at the previous phase of the process. 
At the time of the interview, Company $E$ had not altered its reporting as a result of BBFAW. However, this business has no shareholders and potential investors to scrutinise the results. Furthermore, since BBFAW aligned with their existing values, a change to reporting was not deemed necessary. The respondent in Company $E$ took the view that BBFAW did not add anything to what the customers already knew about the business so the feeling was that it was not needed for discussions within the firm and externally with customers:

We don't need the Benchmark to provide that impetus. Our customers expect us to do the right thing, it's the culture of our business. (Company E).

This position may have been adopted in order to justify Company E's initial mediocre score. It is interesting to note the company's improved scores in the four iterations of BBFAW following the interviews - a rise of three tiers - suggests a change of stance re alignment of external disclosures to BBFAW.

Respondents were asked to name the main stakeholders to whom FAW was important. For Companies $C$ and $E$, customers were the main focus for external communication surrounding FAW. Both of these firms are private companies, so they do not have public investors as a stakeholder group:

We all believe that we've good standards of animal welfare and I think recognition of that, or independent recognition by NGOs, is a great way of being able to show that back to the customers and actually showing that what we are doing is right. (Company $C$ )

The Business Benchmark could be used as a signal of trust to customers that firms can deal with any problems as they arise. (Company E)

Respondents in Company A viewed BBFAW as a signal to investors:

In the market place where we sit for food provenance and a desire to know about animal welfare standards, it's quite low down on our customers' radar... Recording for investors, that's where there's primary motivation... The Benchmark is a signal, in that if you're managing that then it means that you're also managing other things that makes you a well-run business. It's about transparency more than anything. (Company A)

The idea of a signal and validation mechanism is important for two reasons. First, BBFAW provides information about FAW (given the difficulties of definition and measurement) and second, it suggests information about the wider governance of the firm which may serve to build trust and expand connections to new stakeholders. BBFAW is seen as a reinforcement tool, a representation of underlying practice and a signal of good governance in areas beyond FAW. 
For Companies B and D, customers, investors and suppliers were cited as important, indicating that BBFAW is used across key stakeholder groups. For example:

Welfare is inherent within the business but I think BBFAW is another tool which allows me as a welfare manager, to be able to say, "It is important to the customer." But the spread has gone further now, it's about investment as well. I have had a couple of the investor companies wanting to come and discuss where it is now and how important we saw BBFAW. (Company $B$ )

BBFAW is how we talk to our customers; it's how we talk to our stakeholders, including investors that are interested and our farmers who have to help us deliver it. (Company D)

Company D also mentioned a supplier who had cited BBFAW in their communications, showing that it has entered the discourse further up the supply chain:

They actually wrote to my director to say how proud they were about this Business Benchmark and where they have been positioned - which is quite interesting. They saw that we were on the same Business Benchmark and how could we work closer together? (Company D)

The quotes above suggest that BBFAW plays a performative role concerning discourse around FAW between the firms and their stakeholders. BBFAW has succeeded in changing the culture surrounding FAW reporting, in the absence of any mandatory reporting requirements. For the case firms it is becoming the measure of FAW information, connecting stakeholders and making the market. This may be in the form of communication with particular stakeholder groups (as seen above) and disclosure of the actual BBFAW ranking results.

The dynamic repetitive process

As the cycle continues, the creators strive to keep BBFAW relevant by engaging with scientific advisors, investors and with the constituent firms. There is an opportunity for firms to provide feedback on their proposed score, prior to the publication of their results:

They do the report and then you can have that debate in common and you can challenge your scores... The good thing about the Business Benchmark, and there are a number of good things about it, at least you can have that discussion... They do help us find the right solution, you just don't get the right answer on your own... I like the independent benchmarks as long as they're credible and we can have the discussion and we look at it. (Company D)

Between BBFAW publications, the TWG issues a consultation document in order to gather views on proposals for the construction of the subsequent BBFAW. Companies $B, C$ and $E$ mentioned the fact that they had proposed the inclusion of outcome measures (which are now included). Input from the scientific community (for example 
over performance measures) and engagement with investors maximises the potential to strengthen the network links between the three poles of the network.

Within a couple of the firms, a perceived negative aspect of BBFAW related to its construction from public information:

I think what we don't want to do is create something which is really complicated. The only thing I would probably say about the Benchmark was about somebody doing the scoring looking into publicly available information. We don't publish everything that we do. (Company B)

I don't agree with the fact that it only gives what's publicly available so it's not an absolutely fair thing in that we don't make public every nook and cranny what we do. (Company D)

Clearly, welfare is a very complex and emotive issue. Therefore, some limits to disclosure may be desirable, due to the sensitive nature of the welfare information and potential concerns about divulging competitive information. Furthermore, the challenge for firms is that the increasing demands on disclosure placed by successive iterations of BBFAW mean that firms must disclose even more in order to stand still in the ranking results. Extensive demands may push the firms too far, so that BBFAW requirements are ignored. Sensitivity to these issues is required on behalf of the BBFAW creators, in order to ensure that alignment continues and the process remains relevant. However, the counter-argument is that the use of public information may actually be a strength of BBFAW. This point will be discussed in the context of the characteristics for performativity.

\section{Discussion: characteristics required for performativity}

Our review of BBFAW reports and the case study evidence demonstrated that over time there has been an overall improvement in scores, despite the criteria becoming more demanding. During the review period (2012-2017), there has been no change to legislation surrounding FAW that could account for changes in practice. It appears that BBFAW has made FAW more visible, leading to aligned disclosure for a number of firms. As a market device, BBFAW has helped to create a network between the three poles, providing a framework for the definition and measurement of FAW. The evidence suggests that BBFAW possesses many performative features, transforming internal and external narratives for a number of firms. It has become the measure of FAW for the food companies that are engaging in this market.

In terms of improvement underlying FAW practices, we have presented evidence that the lower ranked firm in our case study is starting on the 'journey' as it is using BBFAW to implement a strategy for higher welfare. For the middle-ranked firms, there is evidence that BBFAW is improving decision-making and supplier-side discussions. Higher-ranked firms use BBFAW to assist with decisions over which information to 
publish. For our case firms, there is a clear commitment to BBFAW and its principles. Our discussions have revealed no evidence of greenwashing (Guidry and Paten, 2010; Lyon and Maxwell, 2011; Mahoney et al., 2013; Testa et al., 2018). Internal narratives around BBFAW suggest that the case firms are not 'doing the document rather than doing the doing' (Ahmed, 2007), and they are demonstrating increased accountability rather than simply more accounting (Dillard and Vinnari, 2018). Therefore we would contend that there appears to be no evidence of gaming strategies (Espeland and Sauder, 2007), organised hypocrisy (Cho et al., 2015) or institutional appropriation (Larrinaga-Gonzalez and Bebbington, 2001) as there are improvements being made beyond the external disclosures.

There is a definite pattern of response, with case firms locating at different stages of the performativity process. Overall, we have presented evidence that suggests that the firms that are engaged in FAW are using BBFAW to drive external disclosures, internal decision-making and resource allocation. BBFAW is intervening and shaping the informal rules or culture of the FAW market, thus it has a prospective focus (Brennan and MerklDavies, 2014).

Drawing on the results we propose that there are three characteristics required in order for performativity. Each of these is now discussed in turn.

\section{Common Language}

The quantification of a substantial amount of information into one metric is crucial as it provides a single summary statistic (Callon and Muniesa, 2005), translating the invisible and qualitative (FAW) into the quantitative and visible (Kornberger and Carter, 2010). The metric must represent the market consensus on the measurement of a permanent (non-ephemeral) socially relevant issue, otherwise firms would not invest time and effort in conforming to it. We argue that this consensus is developed along two main dimensions: calculation and communication.

By its nature, FAW is inherently difficult to define and measure. The BBFAW creators decided to construct the benchmark from public disclosures since this would avoid potential accusation of bias or favouritism, enhancing credibility and trust[9]. Furthermore, the rankings can always be calculated since the calculation does not rely on the provision by firms of private information. Construction does not rely on payment for inclusion or on the audit of practices either within the firm or throughout the supply chain, and there are no issues created through the holding by the creators of confidential information, features that can be problematic for assurance schemes. However, the use of narrative disclosures is not uncontroversial, since not all relevant information is published (Berger, 2011). Perhaps some sort of hybrid scheme would appease this criticism but auditing can itself cause conflicts (Messner, 2009) and monitoring costs would have to be factored in to this decision. 
The information communicated in the ranking result must be clear and understandable. The calculation of a single metric, with six defined tiers of performance, assists in the communication of this information, which in its raw form is largely qualitative. An alternative calculation, with an undefined presentation that must be interpreted in some way, would undermine the market consensus, thus diminishing the quality of the tool for classifying, manipulating and ranking of firms (Callon and Law, 2005, p20). Conformation is not an unintended consequence (Espeland and Sauder, 2007), rather it is an explicit aim of BBFAW. This consensus provides the common language for firms to discuss internally and to report externally to stakeholders. Furthermore, continued engagement of the TWG with investors keeps BBFAW at the forefront of minds, with investors using BBFAW as a tool for FAW communication with firms. This engagement by the creators is similar to the actions of Black with his option-pricing model (Mackenzie, 2006a), and it serves to maintain the discourse between market participants (Brennan and Merkl-Davies, 2018).

\section{Building Networks}

With BBFAW as the common language for FAW, the three poles are linked to create the network. The scientific pole is vital to enable BBFAW to reflect research on how FAW should be defined and measured. Companies in the technical pole can then use the benchmark and extend its market reach - through its use internally to help find internal solutions and externally to communicate with stakeholders. However, for some firms, the reach has gone beyond FAW as the evidence demonstrated that BBFAW entities employ their ranking results as an external validation mechanism, not just for FAW but also as a wider signal of good stewardship in other aspects of the business, in order to enhance reputation with stakeholders. A signal of sound risk management practices to providers of finance (equity and debtholders) is desirable (for example it can lead to lower costs of capital, see Abraham and Shrives, 2014).

However, comparability does not mean rigidity, as the creators must work hard in order to ensure that BBFAW remains relevant. Careful construction is required (Gray and Milne, 2015), otherwise there is the scope for 'garbage in and garbage out' (Deegan, 2017). The link between the creators and companies within the technical pole is strengthened through the continued discourse surrounding the development of BBFAW. This reinforces the repetitive process and the fact that BBFAW is itself part of a process. It would have been impossible to introduce a comprehensive and complicated ranking system to the market in a 'big bang' fashion as it is unlikely that the results would have been encouraging for even the most responsible of firms, increasing the probability of failure. The evolutionary stages are apparent, not only in the number of firms included but also in the questions themselves. The introduction of outcome measures from 2017 further reinforces the link to the scientific pole, although it is argued that this link should be strengthened in future iterations.

In Figure 3 we provide a summary of the networks identified by respondents in our case firms. The links between the poles, flowing from the scientific pole to the technical pole 
to the stakeholder pole build the network, with BBFAW as a common language for communication.

Figure 3 about here

\section{Expanding Markets}

The building of networks facilitates the expansion of the market to new actors, thus strengthening performativity. This expansion could be along a number of dimensions, for example through the inclusion of additional companies and new regions in future iterations of BBFAW. The reach of BBFAW may extend to a wider group of customers, suppliers or investors. For example, recent investor engagement via the Global Investor Statement on Farm Animal Welfare extends the reach beyond shareholders of the listed companies to potential future investors, an example of the strengthening and lengthening of a network (Callon et al., 1992). The ranking creates competition within the market (Kornberger and Carter, 2010) with comparability and standardisation enabling its calculation (Callon, 1998). Respondents in companies A, B and D all commented that they made use of BBFAW to draw comparisons with companies that are not necessarily direct competitors. Thus BBFAW expands the market in terms of increasing the number of actors and activities that fall under its umbrella. For a timeseries comparison, the ranking itself must be stable enough to ensure that it is meaningful to draw such appraisals so that it can be reinforced over time. This is particularly important for firms that recognise that they are on a journey, with continued evolution in the performative process.

In summary, BBFAW is an example of a change to the informal rules surrounding the FAW market. It has played and continues to play a performative role, shaping the reality it attempts to monitor (Miller and O'Leary, 2007; Pollock and D'Adderio, 2012). This leads to a gradual alignment of interests through shared frames of reference and language (Slager, 2015), offering new interpretations of a situation (Espeland and Sauder, 2007). Overall we have evidence of increased narrative disclosures and changing behaviour amongst participants in the market (Vesty et al., 2015), creating competition between entities that may not be direct competitors as they compare their results with other firms, thus making and extending markets (Pollock and D'Adderio, 2012).

The limits to performativity

The evidence of firms locating (or more importantly, continuing to locate) in the lower tiers suggests that not all constituent firms are engaging with BBFAW and/or FAW. These firms may have other strategic priorities so they resist improvements in FAW (Dawkins, 2017) and economic factors may lead to a lack of engagement (Milne et al., 2009). The measure may be contested (Sullivan and Hannis, 2017) or even ignored (Messner, 2009) and firms may choose not to publish FAW information (corresponding to BBFAW or at all). Given that many of these companies are located outside of the UK and Europe, it may reflect the underlying views of the (internal and external) stakeholder base. These attitudes would need to change in order to see an improvement in results. Companies 
that are not engaging may be starting the 'journey' to improvements in welfare changes in internal and external narratives, so we cannot yet detect a performative response. Future iterations of BBFAW rankings will reveal whether there has been a performative shift by a greater number of constituent firms.

\section{Conclusions}

Non-human animals and their welfare represent a socially relevant issue that is underrepresented in the accounting literature (Dillard and Vinnari, 2017), yet the intensification of farming methods and perceived injustice to animals are areas of societal concern, with stakeholders demanding improved welfare standards and communication of welfare issues. A difficulty is that animal welfare is not easy to define and measure and since it is not observable by external parties, welfare information must be communicated through disclosures. This form of communication is voluntary, since the Government has not intervened in this aspect of the market by changing the formal rules through legislation and regulation. However, the qualitative nature of farm animal welfare (FAW) information makes it difficult to interpret relative performance.

Within this context, our study has introduced a study of animals into the accounting domain, through the investigation of an attempt to improve FAW in food companies. In particular we have examined a market-based solution to the difficulties surrounding FAW, in the form of an external account, the Business Benchmark on Farm Animal Welfare (BBFAW). Supported by two founding NGOs, BBFAW represents an attempt to raise welfare standards and to improve communication around FAW in a collaborative way, through a global ranking scheme that scores food companies on their narrative disclosures around FAW. Through an investigation of six years of published reports, a review of constituent company websites and a case study of five companies, we have provided rich empirical evidence on the minutiae of the construction and operation of BBFAW. We investigated the scope for BBFAW to reduce transactions (search) costs in the market, through its provision of a solution to the problem of the definition and measurement of FAW. Our investigation was conducted using the framework of performativity - the potential for BBFAW to become the measure of FAW. We suggest that BBFAW acts as an intermediary to create a network linking the scientific (research), technical (BBFAW creators and the companies) and stakeholder poles. Based on our findings, we propose a process of performativity which starts with the recognition of the importance of FAW and BBFAW, followed by changes to internal narratives and commitment of resources, then changes in external narratives. Our findings suggest that the process is dynamic and repetitive, both in terms of constituent firms' response to BBFAW and in respect of the measure itself. Dynamism and repetition are required in order for the measure to evolve so that welfare standards and communication may be improved. Our results provide evidence of these connections and of a performative response in a number of firms, suggesting that BBFAW provides a framework for external disclosures and internal communication and resource allocation. 
The findings led to the articulation of three key characteristics for performativity to arise and be sustained. First is common language, so the measure represents the market consensus concerning calculation and communication of FAW information. Second, the benchmark must be capable of creating a network. Third, the benchmark needs to expand the market, by enabling standardisation, classification and comparisons across firms and over time, creating competition between entities that may not otherwise have been in competition with each other.

Our analysis suggests that a change to informal rules of a market can produce a behavioural response in firms. Formal rules may provide a baseline, however legislation and regulation take time, are costly and they cover limited jurisdictions. Formal rules are also less flexible and adaptable to any changes in norms or expectations. Obsolescence is possible, meaning a loss of resilience. An informal rule can provide new information, enabling firms to differentiate themselves, which would not be possible with baseline legislation. It also establishes further competition in the market, between firms that may not otherwise be seen as competitors. Overall, changes to informal rules can be an effective means of facilitating a change in culture in the market, meaning that formal interference through legislation or regulation is not necessary.

Our study is limited by the fact that the case study evidence was drawn from respondents in companies that were all engaging with FAW and BBFAW, albeit at different stages of the performativity process. Analysis of the reports suggested that there is a subset of firms that continues to locate in the lower tiers. This could be due to either an inability to detect engagement or to an actual lack of engagement. Firms could be using BBFAW as a framework but more time is needed to observe an effect since their FAW 'journey' has just begun. For other firms, it may be that BBFAW does not create a network because FAW is not part of their business strategy so the link between the scientific, technology and market poles is not explicit. These firms are likely to compete along different dimensions (such as price). A second limitation is the fact that we have restricted our investigation to the study of FAW so we have not examined the trade-offs that firms make (for example between the carbon footprint and FAW, or human rights versus animal rights). Further case study research could facilitate a detailed investigation of the performativity process for a firm or firms as they strive to move up the rankings, or examine the 'non-engaged' entities, or the complex decisionmaking process around ethical and sustainability objectives. Finally, the key characteristics of performativity identified in this study could be used to examine other benchmarking schemes. 
1. Whilst we believe passionately in animal welfare and are against factory farming, in this paper we do not take a particular moral stance as to the legitimacy of meat production (compared with, for example Vinnari and Vinnari, 2014; Laine and Vinnari, 2017; Vinnari and Laine, 2017). This is a very complex area that is beyond the scope of our study.

2. The Five Freedoms are: freedom from hunger and thirst, freedom from discomfort, freedom from pain, injury and disease, freedom to express normal behaviour, freedom from fear and distress. The concept of the Five Freedoms originated with the Brambell Report (1965), which led to the formation of the Farm Animal Welfare Advisory Council (now the Farm Animal Welfare Council), (Farm Animal Welfare Council, 2009).

3. This legislation is applicable for firms that operate in and export to the jurisdictions covered by the regulations. Underpinning the importance attributed to animal welfare is the EU Strategy for the Protection and Welfare of Animals 2012-2015, whose purpose is to determine the direction of policies on animal welfare during this time period, and to promote high animal welfare standards in the EU and at the international level (European Union, 2014). The Brexit decision of 2016 has led to calls for animal sentience to be enshrined in new UK legislation.

4. External accounts are also described in a number of other ways, for example counter accounts (Denedo et al., 2017; Laine and Vinnari, 2017; Vinnari and Laine, 2017), shadow accounts (Gallhofer et al., 2006; Dey et al., 2011), and shadow reporting (Tregidga, 2017).

5. Members of the Technical Working Group include representatives from CWF, WAP, animal welfare scientists and funding sponsor Coller Capital (further details can be found in BBFAW 2017, p9).

6. It could be argued that the constituent companies should be in the market pole, as they are not directly involved in the construction of BBFAW. However, we take the view that the companies are part of the technical pole, as they publish the information upon which BBFAW is based, so they have some control over the results.

7. Respondents in the two firms where interviews were not recorded did not want their voices captured. However, they were happy for quotes to be recorded by hand and used in the research.

8. Of the 23 institutional investors, research by the authors revealed that 16 are also signatories to 'Principles for Responsible Investment' (PRI), (Principles for Responsible Investment, 2018) - investors who aim to incorporate environmental, social and governance (ESG) factors into their investment decisions, thereby supporting firms with strong ESG performance (Dyck et al., 2018).

9. For example, bias towards companies with whom CWF and WAP support in areas of FAW. 


\section{References}

Abraham, S. and Shrives, P.J. (2014), "Improving the relevance of risk factor disclosure in corporate annual reports", British Accounting Review, Elsevier Ltd, Vol. 46 No. 1, pp. 91-107.

Adams, C.A. and Whelan, G. (2009), "Conceptualising future change in corporate sustainability reporting", Accounting, Auditing and Accountability Journal, Vol. 22 No. 1, pp. 118-143.

Ahmed, S. (2007), "'You end up doing the document rather than doing': Diversity race equality and the politics of documentation", Ethnic and Racial Studies, available at:https://doi.org/10.1080/01419870701356015.

Animal Welfare Intergroup. (2016), "Eurobarometer", available at: http://www.animalwelfareintergroup.eu/2016/03/16/new-eurobarometer-onattitudes-of-europeans-towards-animal-welfare/ (accessed 15 April 2018).

Animals Australia. (2018), "Animals don't belong here", available at: https://secure.animalsaustralia.org/take_action/live-export-shipboard-cruelty/ (accessed 12 November 2018).

Austin, J. (1962), How to Do Things with Words, Clarenden Press, Oxford.

BBFAW. (2018), "BBFAW Reports 2012-2017", available at: https://www.bbfaw.com/publications/ (accessed 12 February 2018).

Bebbington, J., Larrinaga, C. and Moneva, J.M. (2008), "Corporate social reporting and reputation risk management", Accounting, Auditing \& Accountability Journal, Vol. 21 No. 3, pp. 337-361.

Berger, P. (2011), "Challenges and opportunities in disclosure research - A discussion of 'the financial reporting environment: Review of the recent literature'", Journal of Accounting and Economics, Vol. 51, pp. 204-218.

Boissy, A. and Erhard, H.W. (2014), "How Studying Interactions Between Animal Emotions, Cognition, and Personality Can Contribute to Improve Farm Animal Welfare", Genetics and the Behavior of Domestic Animals, pp. 82-113.

Brambell, R. (1965), Report of the Technical Committee to Enquire into the Welfare of Animals Kept under Intensive Livestock Husbandry Systems, London.

Brennan, N.M. and Merkl-Davies, D.M. (2014), "Rhetoric and argument in social and environmental reporting: The Dirty Laundry case", Accounting, Auditing and Accountability Journal, Vol. 27 No. 4, pp. 602-633.

Brennan, N.M. and Merkl-Davies, D.M. (2018), "Do firms effectively communicate with financial stakeholders? A conceptual model of corporate communication in a capital market context", Accounting and Business Research, Vol. 48 No. 5, pp. 553-577.

Brownell, P. (1995), Research Methods in Management Accounting Issue 2 of Coopers \& Lybrand Accounting Research Methodology Monograph, Coopers and Lybrand Accounting Association of Australia and New Zealand. 
Butler, J. (1993), Bodies That Matter : On the Discursive Limits of "Sex", Routledge, New York.

Cabantous, L., Gond, J.P., Harding, N. and Learmonth, M. (2016), “Critical Essay: Reconsidering critical performativity", Human Relations, Vol. 69 No. 2, pp. 197213.

Cabantous, L., Gond, J.P. and Johnson-Cramer, M. (2010), “Decision theory as practice: Crafting rationality in organizations", Organization Studies, Vol. 31 No. 11, pp. 1531-1566.

Callon, M. (1998), "Introduction: the embeddedness of economic markets in economics", The Editorial Board of The Sociological Review, Blackwell Publishers, Oxford, pp. 1-57.

Callon, M. (2007), "What does it mean to say that economics is performative?", $D$. MacKenzie, F. Muniesa, and L. Siu, Eds. Do Economists Make Markets? On the Performativity of Economics, Princeton University Press, Princeton, NJ, pp. 311 357.

Callon, M., Laredo, P., Rabeharisoa, V., Gonard, T. and Leray, T. (1992), "The management and evaluation of technological programs and the dynamics of techno-economic networks: The case of the AFME", Research Policy, Vol. 21, pp. 215-236.

Callon, M. and Law, J. (2005), "On qualculation, agency, and otherness", Environment and Planning D: Society and Space, Vol. 23 No. 5, pp. 717-733.

Callon, M. and Muniesa, F. (2005), "Peripheral Vision: Economic Markets as Calculative Collective Devices", Organization Studies, Vol. 26 No. 8, pp. 1229-1250.

Chilton, S.M., Burgess, D. and Hutchinson, W.G. (2006), "The relative value of farm animal welfare", Ecological Economics, Vol. 59 No. 3, pp. 353-363.

Cho, C.H., Laine, M., Roberts, R.W. and Rodrigue, M. (2015), "Organized hypocrisy, organizational façades, and sustainability reporting", Accounting, Organizations and Society, Vol. 40, pp. 78-94.

Clark, B., Stewart, G.B., Panzone, L.A., Kyriazakis, I. and Frewer, L.J. (2017), "Citizens, consumers and farm animal welfare: A meta-analysis of willingness-to-pay studies", Food Policy, Vol. 68, pp. 112-127.

Cochoy, F., Giraudeau, M. and McFall, L. (2010), "Performativity, economics and politics: an overview", Journal of Cultural Economy, Vol. 3 No. 2, pp. 139-146.

Crane, A. (1999), "Are You Ethical ? Please Tick Yes D Or No D On Researching Ethics in Business Organizations empiricism", Journal of Business Ethics, Vol. 20 No. 3, pp. 237-248.

CWF. (2013), Compassion in World Farming Strategic Plan 2013-2017.

Dawkins, M. (2015), "Animal welfare and the paradox of animal consciousness", Advances in the Study of Behavior, Vol. 47, pp. 5-38.

Dawkins, M.S. (2012), Why Animals Matter: Animal Consciousness, Animal Welfare, and Human Well-Being, Oxford University Press, Oxford.

Dawkins, M.S. (2017), "Animal welfare and efficient farming: Is conflict inevitable?", Animal Production Science, Vol. 57 No. 2, pp. 201-208.

Deegan, C. (2017), "Twenty five years of social and environmental accounting research 
within Critical Perspectives of Accounting: Hits, misses and ways forward", Critical Perspectives on Accounting, Vol. 43, pp. 65-87.

Deegan, C. and Blomquist, C. (2006), "Stakeholder influence on corporate reporting: An exploration of the interaction between WWF-Australia and the Australian minerals industry", Accounting, Organizations and Society, Vol. 31, pp. 343-372.

Denedo, M., Thomson, I. and Yonekura, A. (2017), "International advocacy NGOs, counter accounting, accountability and engagement", Accounting, Auditing and Accountability Journal, Vol. 30 No. 6, pp. 1309-1343.

Dey, C., Russell, S. and Thomson, I. (2011), "Exploring the potential of shadow accounts in problematizing institutional conduct", in Ball, A. and Osborne, S.P. (Eds.), Social Accounting and Public Management Accountability for the Common Good, Routledge, Oxford, pp. 64-75.

Dillard, J. and Vinnari, E. (2017), "A case study of critique: Critical perspectives on critical accounting", Critical Perspectives on Accounting, Vol. 43, pp. 88-109.

Dillard, J. and Vinnari, E. (2018), "Critical dialogical accountability: From accountingbased accountability to accountability-based accounting", Critical Perspectives on Accounting, available at:https://doi.org/10.1016/j.cpa.2018.10.003.

Dyck, A., Lins, K. V., Roth, L. and Wagner, H.F. (2018), "Do institutional investors drive corporate social responsibility? International evidence", Journal of Financial Economics, Vol. 13 No. 9, pp. 1-22.

Edelman Trust. (2018), “Edelman Trust Special Report: Institutional Investors 2018.", available at: https://www.edelman.co.uk/magazine/posts/edelman-trustbarometer-2018/ (accessed 6 December 2018).

Espeland, W.N. and Sauder, M. (2007), "Rankings and Reactivity: How Public Measures Recreate Social Worlds", American Journal of Sociology, Vol. 113 No. 1, pp. 1-40.

European Union. (2014), "Strategy for the Protection and Welfare of Animals (20122015)", available at: https://ec.europa.eu/food/sites/food/files/animals/docs/aw_eu_strategy_19012 012_en.pdf (accessed 5 April 2018).

Farm Animal Welfare Council. (2009), "Farm Animal Welfare Council report on Farm Animal Welfare in Great Britain (2009)", available at: https://www.gov.uk/government/publications/fawc-report-on-farm-animalwelfare-in-great-britain-past-present-and-future (accessed 31 July 2015).

Fligstein, N. (2001), "Markets as Institutions", The Architecture of Markets: An Economic Soliology of Twenty-First Century Capitalist Societies, pp. 27-44.

Gallhofer, S., Haslam, J., Monk, E. and Roberts, C. (2006), "The emancipatory potential of online reporting: The case of counter accounting", Accounting, Auditing \& Accountability Journal, Vol. 19 No. 5, pp. 681-718.

Giamporcaro, S. and Gond, J.P. (2016), "Calculability as Politics in the Construction of Markets: The Case of Socially Responsible Investment in France", Organization Studies, Vol. 37 No. 4, pp. 465-495.

Gond, J.-P., Cabantous, L., Harding, N. and Learmonth, M. (2015), "What do we mean by performativity in organizational and management theory? The uses and abuses of performativity", International Journal of Management Review, Vol. 00, pp. 1- 
24.

Gray, R. (2010), "Is accounting for sustainability actually accounting for sustainability...and how would we know? An exploration of narratives of organisations and the planet", Accounting, Organizations and Society, Vol. 35, pp. 47-62.

Gray, R. (2013), "Back to basics: what do we mean by environmental (and social) accounting and what is it for? - a reaction to Thornton", Critical Perspectives on Accounting, Vol. 24 No. 6, pp. 459-468.

Gray, R. and Milne, M.J. (2015), "It's not what you do, it's the way that you do it? Of method and madness", Critical Perspectives on Accounting, Elsevier Ltd, Vol. 32, pp. 51-66.

Greiveldinger, L., Veissier, I. and Boissy, A. (2011), "The ability of lambs to form expectations and the emotional consequences of a discrepancy from their expectations", Psychoneuroendocrinology, available at:https://doi.org/10.1016/j.psyneuen.2010.11.002.

Guidry, R. and Paten, D. (2010), "Market reactions to the first-time issuance of corporate sustainability reports: Evidence that quality matters", Sustainability Accounting, Management and Policy Journal, Vol. 1 No. 1, pp. 33-50.

Guthrie, J. and Parker, L.D. (2017), "Reflections and projections: 30 years of the interdisciplinary accounting, auditing and accountability search for a fairer society", Accounting, Auditing and Accountability Journal, Vol. 30 No. 1, pp. 2-17.

Harvey, D. and Hubbard, C. (2013), "Reconsidering the political economy of farm animal welfare: An anatomy of market failure", Food Policy, Vol. 38 No. 1, pp. 105-114.

Islam, M.A. and van Staden, C. (2018), "Social movement NGOs and the comprehensiveness of conflict mineral disclosures: evidence from global companies", Accounting, Organizations and Society, Vol. 65, pp. 1-19.

Jeacle, I. and Carter, C. (2011), "In TripAdvisor we trust: Rankings, calculative regimes and abstract systems", Accounting, Organizations and Society, Elsevier Ltd, Vol. 36 No. 4-5, pp. 293-309.

Karpik, L. (2010), Valuing the Unique. The Economics of Singularities, Princeton University Press, Princeton.

Knowles, L. and Heanue, S. (2019), "Australian cattle exported to Sri Lanka dying and malnourished, local farmers left suicidal", $A B C$ News, available at: https://www.abc.net.au/news/2019-04-04/australian-dairy-cattle-sent-to-srilanka-dying-malnourished/10936258 (accessed 9 April 2019).

Kornberger, M. and Carter, C. (2010), "Manufacturing competition: How accounting practices shape strategy making in cities", Accounting, Auditing and Accountability Journal, Vol. 23 No. 3, pp. 325-349.

Lagerkvist, C.J. and Hess, S. (2011), "A meta-analysis of consumer willingness to pay for farm animal welfare", European Review of Agricultural Economics, Vol. 38 No. 1, pp. 55-78.

Laine, M. and Vinnari, E. (2017), "The transformative potential of counter accounts: a case study of animal rights activism", Accounting, Auditing and Accountability 
Journal, Vol. 30 No. 7, pp. 1481-1510.

Larrinaga-Gonzalez, C. and Bebbington, J. (2001), "Accounting change or institutional appropriation? - A case study of the implementation of environmental accounting", Critical Perspectives on Accounting, Vol. 12 No. 3, pp. 269-292.

Lyon, T.P. and Maxwell, J.W. (2011), "Greenwash: Corporate environmental disclosure under threat of audit", Journal of Economics and Management Strategy, Vol. 20 No. 1, pp. 3-41.

Mackenzie, D. (2003), "An Equation and its Worlds : Bricolage , Exemplars, Disunity and in Financial Economics Performativity", Social Studies of Science, Vol. 33 No. 6, pp. 831-868.

Mackenzie, D. (2006a), "Is Economics Performative? Option Theory and the Construction of Derivatives Markets", Journal of the History of Economic Thought, Vol. 28 No. 1, pp. 29-55.

Mackenzie, D. (2006b), An Engine, Not a Camera : How Financial Models Shape Markets, MIT Press, Cambridge, MA.

Mackenzie, D. and Millo, Y. (2003), "Constructing a Market, Performing Theory: Derivatives Exchange 1", American Journal of Sociology, Vol. 109 No. 1, pp. 107145.

Mahoney, L.S., Thorne, L., Cecil, L. and LaGore, W. (2013), “A research note on standalone corporate social responsibility reports: Signaling or greenwashing?", Critical Perspectives on Accounting, Vol. 24, pp. 350-359.

Martin, G. and Blache, D. (2014), Review of Animal Welfare QA Systems for Livestock Industries in the UK and Europe: Identification of the Possibilities for the Red Meat Industries of Australia, Vol. 364.

McCulloch, S.P. (2013), "A Critique of FAWC's Five Freedoms as a Framework for the Analysis of Animal Welfare", Journal of Agricultural and Environmental Ethics, Vol. 26 No. 5, pp. 959-975.

McLaren, J., Appleyard, T. and Mitchell, F. (2016), "The rise and fall of management accounting systems: A case study investigation of EVA ${ }^{\mathrm{TM}}$ ", British Accounting Review, Vol. 48 No. 3, available at:https://doi.org/10.1016/j.bar.2016.02.001.

Messner, M. (2009), "The limits of accountability", Accounting, Organizations and Society, Elsevier Ltd, Vol. 34 No. 8, pp. 918-938.

Miller, P. (2001), "Governing by Numbers: Why Calculative Practices Matter", Social Research, Vol. 68 No. 2, pp. 379-396.

Miller, P. and O'Leary, T. (2007), “Mediating instruments and making markets: Capital budgeting, science and the economy", Accounting, Organizations and Society, Vol. 32, pp. 701-734.

Milne, M.J., Tregidga, H. and Walton, S. (2009), "Words not actions! The ideological role of sustainable development reporting", Accounting, Auditing and Accountability Journal, available at:https://doi.org/10.1108/09513570910999292.

Muniesa, F., Millo, Y. and Callon, M. (2007), "An introduction to market devices", Sociological Review, Vol. 55 No. SUPPL. 2, pp. 1-12.

North, D. (1990), Institutions, Institutional Change and Economic Performance, Cambridge University Press, Cambridge. 
Otley, D. (1999), "Performance management: a framework for management control systems research", Management Accounting Research, Vol. 22 No. 3, pp. 259281.

Owen, D. (2008), “Chronicles of wasted time?: A personal reflection on the current state of, and future prospects for, social and environmental accounting research", Accounting, Auditing \& Accountability Journal, Vol. 21 No. 2, pp. 240-267.

Pollock, N. and D'Adderio, L. (2012), "Give me a two-by-two matrix and I will create the market: Rankings, graphic visualisations and sociomateriality", Accounting, Organizations and Society, Elsevier Ltd, Vol. 37, pp. 565-586.

Pollock, N., D’Adderio, L., Williams, R. and Leforestier, L. (2018), “Conforming or transforming? How organizations respond to multiple rankings", Accounting, Organizations and Society, Elsevier, Vol. 64, pp. 55-68.

Principles for Responsible Investment. (2018), "PRI Signatories", available at: https://www.unpri.org/signatories (accessed 20 January 2019).

Revellino, S. and Mouritsen, J. (2015), "Accounting as an engine: The performativity of calculative practices and the dynamics of innovation", Management Accounting Research, Elsevier Ltd, Vol. 28, pp. 31-49.

Rooney, J. and Dumay, J. (2016), "Intellectual capital, calculability and qualculation", British Accounting Review, Elsevier Ltd, Vol. 48 No. 1, pp. 1-16.

Roscoe, P. and Chillas, S. (2014), "The state of affairs: critical performativity and the online dating industry", Organization, Vol. 21 No. 6, pp. 797-820.

Sauder, M. and Espeland, W.N. (2009), "The Discipline of Rankings: Tight Coupling and Organizational Change", American Sociological Review, Vol. 74 No. 1, pp. 63-82.

Scapens, R.W. (1990), "Researching management accounting practice: The role of case study methods", The British Accounting Review, Vol. 22 No. 3, pp. 259-281.

Schultz, M., Mouritsen, J. and Gabrielsen, G. (2001), "Sticky Reputation: Analyzing a Ranking System", Corporate Reputation Review, Vol. 4 No. 1, pp. 24-41.

Shore, C. and Wright, S. (2015), "Governing by numbers: Audit culture, rankings and the new world order", Social Anthropology, Vol. 23 No. 1, pp. 22-28.

Skærbæk, P. and Tryggestad, K. (2010), "The role of accounting devices in performing corporate strategy", Accounting, Organizations and Society, Vol. 35 No. 1, pp. 108-124.

Slager, R. (2015), "SRI Indices and Responsible Corporate Behavior: A Study of the FTSE4Good Index", Business and Society, Vol. 54 No. 3, pp. 386-405.

Sullivan, S. and Hannis, M. (2017), "'Mathematics maybe, but not money': On balance sheets, numbers and nature in ecological accounting", Accounting, Auditing and Accountability Journal, Vol. 30 No. 7, pp. 1459-1480.

Testa, F., Boiral, O. and Fabio, I. (2018), "Internalization of Environmental Practices and Institutional Complexity: Can Stakeholders Pressures Encourage Greenwashing?", Journal of Business Ethics, Vol. 147 No. 2, pp. 287-307.

Thomson, I., Dey, C. and Russell, S. (2015), "Activism, arenas and accounts in conflicts over tobacco control", Accounting, Auditing and Accountability Journal, Vol. 28 No. 5, pp. 809-845.

Tilman, D., Fargione, J., Wolff, B., D’Antonio, C., Dobson, A., Howarth, R., Schindler, D., 
et al. (2001), "Forecasting Agriculturally Driven Global Environmental Change", Science, Vol. 292, pp. 281-284.

Tourish, D. and Willmott, H. (2015), "In Defiance of Folly: Journal rankings, mindless measures and the ABS Guide", Critical Perspectives on Accounting, Vol. 26, pp. 37-46.

Tregidga, H. (2017), "'Speaking truth to power': analysing shadow reporting as a form of shadow accounting", Accounting, Auditing and Accountability Journal, Vol. 30 No. 3, pp. 510-533.

UK Government. (2017), “Guidance: Animal Welfare”, available at: https://www.gov.uk/guidance/animal-welfare (accessed 7 January 2019).

United Nations. (2017), "No Titl", available at:

https://www.un.org/development/desa/en/news/population/world-populationprospects-2017.html (accessed 30 December 2018).

Vesty, G.M., Telgenkamp, A. and Roscoe, P.J. (2015), “Creating numbers: Carbon and capital investment", Accounting, Auditing and Accountability Journal, Vol. 28 No. 3, pp. 302-324.

Vinnari, E. and Laine, M. (2017), "The moral mechanism of counter accounts: The case of industrial animal production", Accounting, Organizations and Society, Vol. 57, pp. 1-17.

Vinnari, M. and Vinnari, E. (2014), "A Framework for Sustainability Transition: The Case of Plant-Based Diets", Journal of Agricultural and Environmental Ethics, Vol. 27, pp. 369-396.

Vosselman, E. (2014), "The performativity thesis and its critics: Towards a relational ontology of management accounting", Accounting and Business Research, Taylor \& Francis, Vol. 44 No. 2, pp. 181-203.

Webster, J. (2013), "Animal welfare in New Zealand pastoral industries. A growing need to do it well", Primary Industry Management, Vol. 17 No. 1, pp. 23-28.

Willmott, H. (2011), "Journal list fetishism and the perversion of scholarship: Reactivity and the ABS list", Organization, Vol. 18 No. 4, pp. 429-442.

Yarrow, G. (2015), The Political Economy of Markets, available at: www.rpieurope.org.

Yin, R. (2018), Case Study Research Design and Methods (6th Ed.), Sage Publications, California. 
Tables and Figures

Table 1: Summary information on case study firms and interviews

\begin{tabular}{|c|l|l|c|c|c|}
\hline $\begin{array}{c}\text { Company } \\
\text { Identification }\end{array}$ & ICB Classification* & $\begin{array}{l}\text { Type of } \\
\text { firm }\end{array}$ & $\begin{array}{c}\text { 2014 Revenue } \\
\text { (fm)** }\end{array}$ & Interviewee/s role & $\begin{array}{l}\text { Interview Date } \\
\text { and Length }\end{array}$ \\
\hline A & $\begin{array}{l}\text { 5757: Restaurants } \\
\text { and Bars }\end{array}$ & $\begin{array}{c}\text { UK Listed } \\
\text { plc } \\
\text { (FTSE250) }\end{array}$ & 804 & $\begin{array}{c}\text { Social } \\
\text { Responsibility } \\
\text { Manager plus } \\
\text { Agriculture } \\
\text { Manager }\end{array}$ & $\begin{array}{c}\text { June } 2014 \\
74 \text { minutes }\end{array}$ \\
\hline B & $\begin{array}{l}5337: \text { Food } \\
\text { Retailers and } \\
\text { Wholesalers }\end{array}$ & $\begin{array}{c}\text { UK Listed } \\
\text { plc } \\
\text { (FTSE100) }\end{array}$ & 10,310 & $\begin{array}{c}\text { Animal Welfare } \\
\text { Manager }\end{array}$ & $\begin{array}{c}\text { May } 2014 \\
120 \text { minutes }\end{array}$ \\
\hline C & $\begin{array}{l}\text { 3570: Food } \\
\text { Producer }\end{array}$ & $\begin{array}{c}\text { UK } \\
\text { Private }\end{array}$ & 577 & $\begin{array}{c}\text { Produce and Farms } \\
\text { Director plus } \\
\text { Technical Director }\end{array}$ & $\begin{array}{c}\text { April } 2014 \\
120 \text { minutes }\end{array}$ \\
\hline D & $\begin{array}{l}5337: \text { Food } \\
\text { Retailers and } \\
\text { Wholesalers }\end{array}$ & $\begin{array}{c}\text { UK Listed } \\
\text { plc } \\
\text { (FTSE100) }\end{array}$ & 26,353 & Agriculture \\
Manager & $\begin{array}{c}\text { April } 2014 \\
89 \text { minutes }\end{array}$ \\
\hline E & $\begin{array}{l}\text { 5337: Food } \\
\text { Retailers and } \\
\text { Wholesaler }\end{array}$ & $\begin{array}{c}\text { UK } \\
\text { Private }\end{array}$ & 5,754 & Sustainability \\
Manager & $\begin{array}{c}\text { April } 2014 \\
110 \text { minutes }\end{array}$ \\
\hline
\end{tabular}

* Source: BBFAW reports

** Source: Company accounts

Table 2: Summary Results from BBFAW reports (2012-2017)

\begin{tabular}{|c|c|c|c|c|c|c|}
\hline & $\mathbf{2 0 1 7}$ & $\mathbf{2 0 1 6}$ & $\mathbf{2 0 1 5}$ & $\mathbf{2 0 1 4}$ & $\mathbf{2 0 1 3}$ & $\mathbf{2 0 1 2}$ \\
\hline Number of firms & 110 & 99 & 90 & 80 & 70 & 68 \\
\hline Tier 1 & 5 & 6 & 4 & 3 & 2 & 0 \\
\hline Tier 2 & 12 & 7 & 7 & 7 & 5 & 3 \\
\hline Tier 3 & 29 & 22 & 16 & 14 & 10 & 6 \\
\hline Tier 4 & 23 & 22 & 27 & 16 & 16 & 18 \\
\hline Tier 5 & 20 & 24 & 17 & 19 & 14 & 18 \\
\hline Tier 6 & 21 & 18 & 19 & 21 & 23 & 23 \\
\hline $\begin{array}{c}\text { Average Tier } \\
\text { Value }\end{array}$ & $\mathbf{3 . 9 5}$ & $\mathbf{4 . 0 6}$ & $\mathbf{4 . 1 2}$ & $\mathbf{4 . 3 2}$ & $\mathbf{4 . 4 4}$ & $\mathbf{4 . 7 2}$ \\
\hline $\begin{array}{c}\text { Average Score } \\
\text { Improvement } \\
\text { on score from } \\
\text { Previous Year }\end{array}$ & $37 \%$ & $34 \%$ & $33 \%$ & $30 \%$ & $28 \%$ & $23 \%$ \\
\hline
\end{tabular}




\begin{tabular}{|c|c|c|c|c|c|c|}
\hline $\begin{array}{c}\text { Firms publishing } \\
\text { FAW policy }\end{array}$ & $72 \%$ & $73 \%$ & $69 \%$ & $53 \%$ & $51 \%$ & $46 \%$ \\
\hline
\end{tabular}

(Source: BBFAW17 p19; BBFAW16 p 10; BBFAW15, p9; BBFAW14, p26; BBFAW13, p9; BBFAW12 p17 and authors' calculations).

Table 3: External narratives: number of 2017 BBFAW firms mentioning BBFAW (online disclosures)

\begin{tabular}{|c|c|c|}
\hline Tier & $\begin{array}{l}\text { Number of } \\
\text { firms } \\
\text { mentioning } \\
\text { BBFAW out of } \\
\text { total in tier }\end{array}$ & Example Statements \\
\hline 1 & $5 / 5$ & $\begin{array}{l}\text { Cranswick: 'Retaining the Tier One level for the second consecutive year is also } \\
\text { demonstrative of our sustained commitment to animal welfare'. } \\
\text { Marks \& Spencer: 'We welcome the role that the BBFAW Benchmark provides in } \\
\text { being a catalyst across for change across the whole food sector'. } \\
\text { Waitrose: 'The Business Benchmark on Farm Animal Welfare (BBFAW) is the first } \\
\text { global benchmark of company performance on this issue. Since launching in } 2012 \\
\text { it has positively influenced corporate practices on welfare management and } \\
\text { reporting'. }\end{array}$ \\
\hline 2 & $11 / 12$ & $\begin{array}{l}\text { Cargill: 'The } 2016 \text { report validates Cargill's commitment to animal welfare best } \\
\text { practices, policies, processes and performance'. } \\
\text { Greggs: 'We measure our progress against the Business Benchmark on Farm } \\
\text { Animal Welfare (BBFAW) which is the leading global measure of company } \\
\text { performance on welfare'. } \\
\text { Perdue Farms: 'The Business Benchmark aligns our vision to be the most-trusted } \\
\text { name in premium protein and provides independent third party recognition of } \\
\text { our progress. We share a common goal in improving farm animal welfare'. } \\
\text { Sainsbury: 'We are proud to be one of only } 11 \text { global companies listed in the top } \\
2 \text { tiers of this benchmark in } 2015 \text { '. ( } 2016 \text { annual report) }\end{array}$ \\
\hline 3 & $5 / 29$ & $\begin{array}{l}\text { Compass: 'Compass fully supports the principles of the FAWC Five Freedoms and } \\
\text { Business Benchmark on Farm Animal Welfare (BBFAW) beliefs'. } \\
\text { Premier Foods: 'We are delighted that our efforts have been independently } \\
\text { evaluated and acknowledged in the } 2016 \text { BBFAW report'. }\end{array}$ \\
\hline 4 & $0 / 23$ & No published statements relating to FAW in Tier 4 companies \\
\hline 5 & $0 / 20$ & No published statements relating to FAW in Tier 5 companies \\
\hline 6 & $0 / 21$ & No published statements relating to FAW in Tier 6 companies \\
\hline
\end{tabular}

(Source: Authors' analysis of company websites, conducted January-April 2018) 
Figure 1: BBFAW as the intermediary linking the three network poles

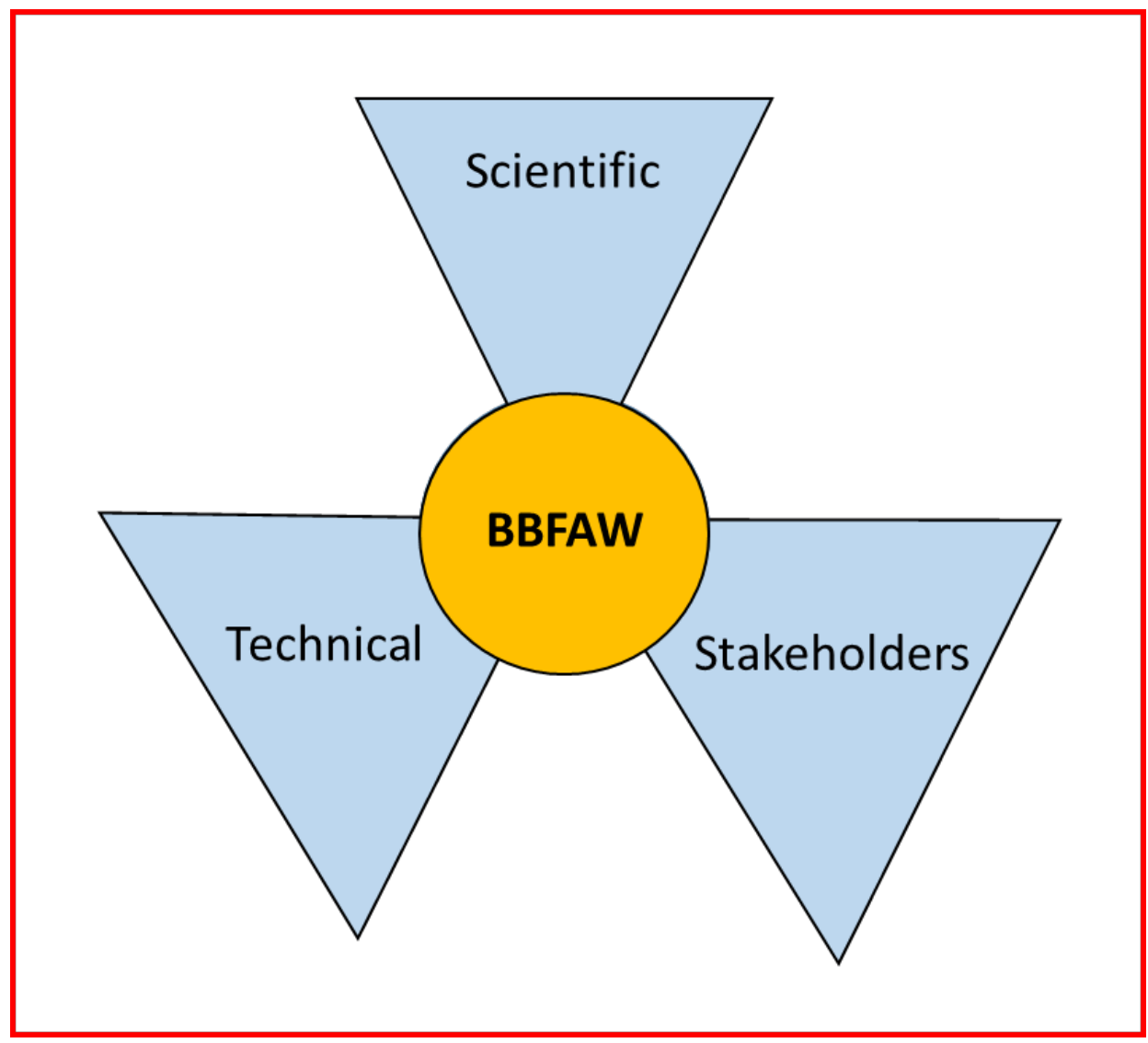


Figure 2: The Process of Performativity

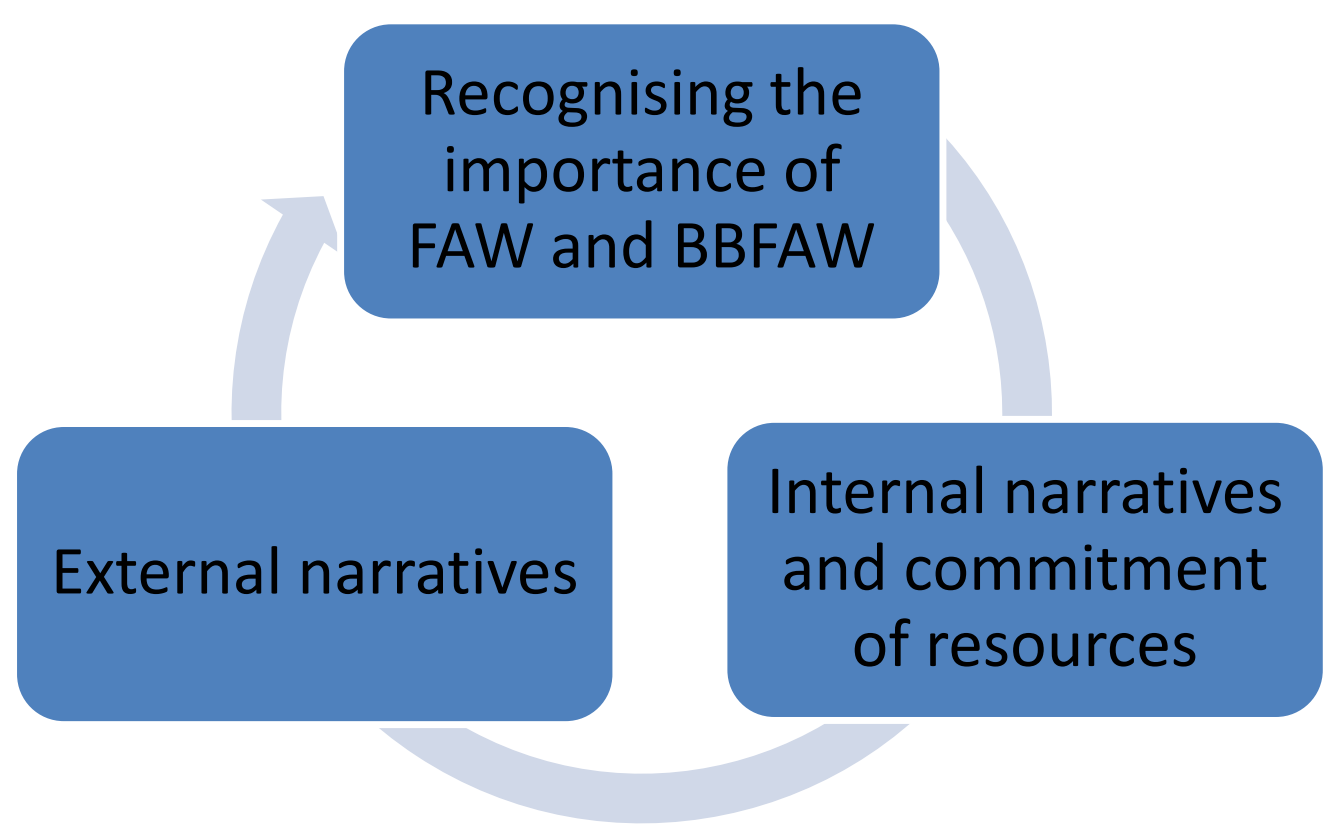


Figure 3: Case study evidence - BBFAW creating network links as identified by case companies

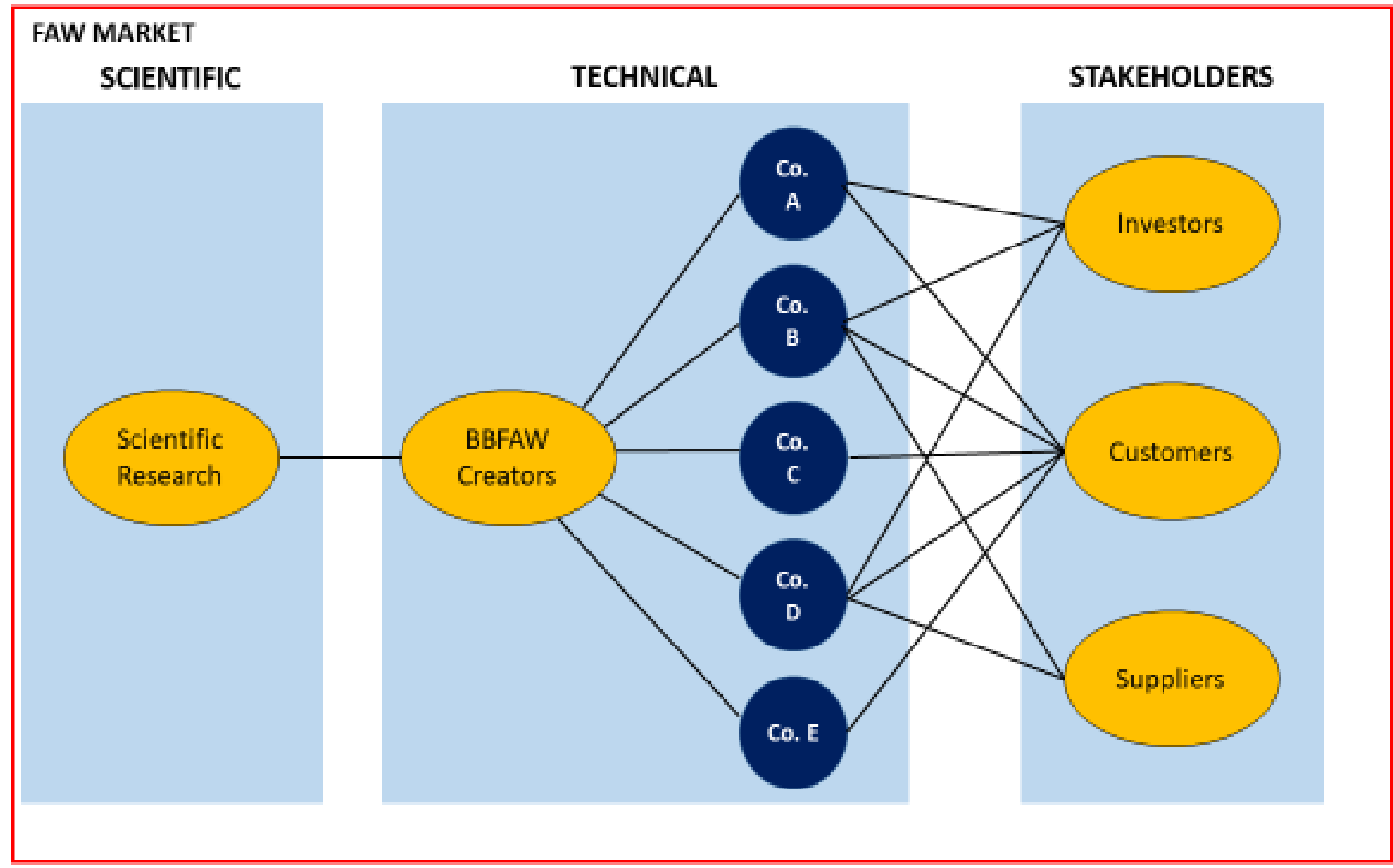

*Stakeholders in the market could belong to a number of groups, e.g. an individual could be an investor, customer and supplier in a particular company. 